\title{
Kraft lignin and polyethylene terephthalate blends: effect on thermal and mechanical properties
}

\author{
Lívia Lazzari', Eloilson Domingos ${ }^{1,2}$, Letícia Silva ${ }^{3,4}$, Alexei Kuznetsov ${ }^{3}$, Wanderson Romão ${ }^{1,2}$ \\ and Joyce Araujo ${ }^{3 *}$ (D)

\begin{abstract}
${ }^{1}$ Laboratório de Química Analítica, Instituto de Química, Instituto Federal de Educação, Ciência e Tecnologia do Espírito Santo - IFES, Vila Velha, ES, Brasil

${ }^{2}$ Laboratório Petroleômico e Forense, Departamento de Química, Universidade Federal do Espírito Santo - UFES, Vitória, ES, Brasil
\end{abstract} \\ ${ }^{3}$ Divisão de Metrologia de Materiais, Instituto Nacional de Metrologia, Qualidade e Tecnologia - Inmetro, \\ Duque de Caxias, RJ, Brasil \\ ${ }^{4}$ Universidade Federal do Rio de Janeiro - UFRJ, Duque de Caxias, RJ, Brasil \\ *jraraujo@inmetro.gov.br
}

\begin{abstract}
In this work, bottle-grade poly(ethylene terephthalate) $\left(\mathrm{PET}_{\mathrm{R}}\right)$, kraft lignin $(\mathrm{KL})$, and chemically modified lignin (ML) were used to form blends to improve the mechanical and thermal properties of pure PET. The PET/KL and PET ${ }_{R} / \mathrm{ML}$ blends were produced with $0.5,1,3$, and $5 \mathrm{wt} . \%$ of lignin via melt extrusion and injection molding. The produced blends and $\mathrm{PET}_{\mathrm{R}}$ were characterized by Fourier transform infrared spectroscopy (FTIR), thermogravimetry (TGA), differential scanning calorimetry (DSC) and mechanical properties testing. The FTIR measurements confirmed the chemical modifications of the ML samples, while the TGA results showed KL to be thermally more stable than ML. The glass transition temperature of $\mathrm{PET}_{\mathrm{R}}$ changed as a function of the amount of lignin, as revealed by the DSC measurements. The PET/KL blends demonstrated their potential for use as an engineering material due to their improved thermal and mechanical properties compared to those of $\mathrm{PET}_{\mathrm{R}}$.
\end{abstract}

Keywords: blends, kraft lignin, mechanical properties, poly(ethylene terephthalate).

How to cite: Lazzari, L., Domingos, E., Silva, L., Kuznetsov, A., Romão, W., \& Araujo, J. (2019). Kraft lignin and polyethylene terephthalate blends: effect on thermal and mechanical properties. Polímeros: Ciência e Tecnologia, 29(4), e2019055. https://doi.org/10.1590/0104-1428.06618

\section{Introduction}

Synthetic or petroleum-based polymers have many practical uses; however, their low biodegradability causes serious environmental problems. Consequently, several strategies to replace or reduce the use of synthetic polymers have been developed ${ }^{[1-4]}$. Sustainable development requirements open new perspectives for products obtained from polymer recycling processes, as they significantly contribute to a reduction in plastic waste ${ }^{[5]}$.

Polyethylene terephthalate (PET) is a semi-crystalline thermoplastic aromatic polyester known for its mechanical properties, lightness, strength, and high transparency, which ensure its widespread use in food and cosmetic packaging materials ${ }^{[2,6-10]}$. Currently, recycled PET is often mixed with other polymers or fillers to produce polymer blends or composites with different mechanical and thermal properties compared to neat polymers, thus adding value to raw materials. For added-value processes to be consistently efficient, the compatibility between mixture components is highly essential to achieve satisfactory thermal and mechanical properties for a specific application ${ }^{[11-13]}$. Mechanical enhancements may be useful to the automobile and civil construction industries, while improvements of thermal stability would be useful for applications in the packaging and electronics industries.

Lignin is one of the three main constituents of a plant. It is the second most abundant polymer in the world after cellulose. Generally, its structure depends on the species of wood and the processing conditions. Kraft, sulfite, and soda are the main processes used in chemical wood pulping for extracting cellulose from wood by dissolving the lignin that binds the cellulose fibers together ${ }^{[14,15]}$.

The kraft pulping process involves digesting wood chips and moiled paper at elevated temperature and pressure in a water solution of sodium sulfide and sodium hydroxide, called "white liquor." The white liquor chemically dissolves the lignin that binds the cellulose fibers together. Spent "white liquor," containing suspended particulate solids and organic compounds, is concentrated to a mostly solid pulp, called "black liquor," which contains between 10 to $50 \mathrm{wt} . \%$ of dissolved lignin ${ }^{[14,16,17]}$. Today, most of the lignin produced by the pulp and paper industry as a constituent part of the black liquor by-product is burned to provide heat for electric power generation. However, as lignin is a complex polyfunctional 
macromolecule composed of a large number of polar functional groups, it has the potential for use in several technological applications and can be used to produce high-added-value products $^{[18-20]}$.

Blending lignin with a polymeric matrix is a secure way to develop polymer-based products with desirable properties. However, the eventual incompatibility on a chemical level between the components may require the chemical modification of lignin before mixing to improve its dispersion in plastic or to increase interfacial adhesion ${ }^{[14,17,21,22]}$.

This work aimed to develop a new engineering material with enhanced mechanical and thermal properties using waste PET bottles and lignin, which was obtained as a by-product of the kraft process. The PET/lignin blends were produced by melt extrusion and injection molding and contained chemically modified and unmodified lignin. The thermal and mechanical properties of the blends were compared with those of the $\mathrm{PET}_{\mathrm{R}}$ matrix.

\section{Materials and Methods}

\subsection{Materials}

Lignin from the kraft process, referred to here as KL, was supplied by Fibria Celulose S/A (São Paulo, Brazil). Chemical modification of the lignin was accomplished using ethylic alcohol 95\% (v/v) (CAS 64-17-5), sodium hydroxide 97\% (wt/wt) (CAS 1310- 73-2), and monochloroacetic acid 99\% (wt/wt) (CAS 79-11-8), all supplied by Sigma Aldrich.

Lignin was extracted from the black liquor via a precipitation method that consisted of the following steps: reduction of the liquor $\mathrm{pH}$ value (start solution was $\mathrm{pH}>13$ ) with $\mathrm{CO}_{2}$ injection, filtration of the precipitated lignin, suspension of the filtered lignin in $\mathrm{a}_{2} \mathrm{SO}_{4}$ solution $(\mathrm{pH} 2.5)$, and filtration and washing of the lignin with an acidic solution ( $\mathrm{pH} 2.5$ and $\left.60^{\circ} \mathrm{C}\right)$.

The bottle-grade PET $\left(\mathrm{PET}_{\mathrm{R}}\right)$ was obtained by grinding colorless PET bottles in a Retsch mill (model SM300) with a $2 \mathrm{~mm}$ sieve and $1500 \mathrm{rpm}$ rotation. Prior to milling, the bottle labels were removed, and the areas with glue residue were cleaned.

\subsection{Lignin modification}

The lignin modification was performed as described by Silva et al. ${ }^{[23]}$. Briefly, $10.0 \mathrm{~g}$ of lignin was suspended in $270 \mathrm{~mL}$ of $95 \%$ ethanol (v/v) under continuous stirring in a mechanical stirrer (Ethik Technology, model 105) to which $27 \mathrm{~mL}$ of a $30 \% \mathrm{NaOH}$ aqueous solution (wt/v) was added at a rate of $1 \mathrm{~mL} \mathrm{~min}^{-1}$ using an electronic pipette (Transferpette $\mathrm{S}$ ) at room temperature. After the addition of the $\mathrm{NaOH}$ solution, the final solution was stirred for a further $60 \mathrm{~min}$. Subsequently, $12.0 \mathrm{~g}$ of monochloroacetic acid was gradually added over the course of $30 \mathrm{~min}$, without further agitation of the solution. The mixture was then stirred for an additional $210 \mathrm{~min}$ at $55^{\circ} \mathrm{C}$. The residue was suspended in $670 \mathrm{~mL}$ of $95 \%$ ethanol solution (v/v), which was neutralized with glacial acetic acid, and the separated product was filtered. After filtration, the product was washed three times with approximately $50 \mathrm{~mL}$ of $95 \%$ ethanol (v/v) to remove the impurities and by-products and then dried at $60{ }^{\circ} \mathrm{C}$ in an oven until a constant mass was achieved. The modified lignin is denominated in this work as $\mathrm{ML}^{[23]}$.

\subsection{Specimen preparation}

Milled $\mathrm{PET}_{\mathrm{R}}, \mathrm{KL}$, and ML samples were dried in a vacuum oven at $60{ }^{\circ} \mathrm{C}$ for $24 \mathrm{~h}$ prior to melting extrusion and injection molding.

The $\mathrm{PET}_{\mathrm{R}}$ /lignin blends were fabricated by extrusion using a Thermo Scientific Haake MiniLab II extruder (processing temperature $275^{\circ} \mathrm{C}$ and screw rotation speed $100 \mathrm{rpm}$ ). The reference specimens $\left(\mathrm{PET}_{\mathrm{R}}\right)$ and its blends were injected into a Thermo Scientific Haake MiniJet II injector (injection temperature $275^{\circ} \mathrm{C}$, injection pressure 450 bar, injection time $4 \mathrm{~s}$ and molding temperature $25^{\circ} \mathrm{C}$ ). Table 1 displays the formulations of the specimens.

\subsection{FTIR}

The attenuated total reflectance Fourier transform infrared (ATR-FTIR) spectra were obtained on a Frontier spectrometer from Perkin Elmer. Each spectrum was recorded as the mean of 16 consecutive scans, with a resolution of $4 \mathrm{~cm}^{-1}$ in a working range of 4000 to $630 \mathrm{~cm}^{-1}$.

\subsection{Thermogravimetry (TGA)}

Thermogravimetry analysis (TGA) was performed on an SDT Q600 from TA Instruments. Approximately $10 \mathrm{mg}$ of the sample was heated in the alumina crucible $\left(25^{\circ} \mathrm{C}\right.$ to $\left.900{ }^{\circ} \mathrm{C}\right)$ at a heating rate of $10{ }^{\circ} \mathrm{C} \mathrm{min}-1$ under a nitrogen flow of $20 \mathrm{~mL} \mathrm{~min}^{-1}$.

\subsection{Differential Scanning Calorimetry (DSC)}

Differential scanning calorimetry (DSC) was carried out using a TA Instruments Q200. Approximately $5 \mathrm{mg}$ of the

Table 1. Composition of the formulations used to fabricate the tensile specimens.

\begin{tabular}{|c|c|c|c|c|}
\hline Sample & PET $_{\mathrm{R}}$ (wt.\%) & KL (wt.\%) & ML (wt.\%) & Formulation* \\
\hline 1 & 100 & 0 & 0 & $\mathrm{PET}_{\mathrm{R}}$ \\
\hline 2 & 99.5 & 0.5 & 0 & PET/KF 0.5 wt. $\%$ \\
\hline 3 & 99 & 1.0 & 0 & PET/KF 1.0 wt. $\%$ \\
\hline 4 & 97 & 3.0 & 0 & PET/KF 3.0 wt. $\%$ \\
\hline 5 & 95 & 5.0 & 0 & PET/KF 5.0 wt. $\%$ \\
\hline 6 & 99.5 & 0 & 0.5 & PET/ML 0.5 wt. $\%$ \\
\hline 7 & 99 & 0 & 1.0 & PET/ML 1.0 wt.\% \\
\hline 8 & 97 & 0 & 3.0 & PET/ML 3.0 wt. $\%$ \\
\hline 9 & 95 & 0 & 5.0 & PET/ML 5.0 wt.\% \\
\hline
\end{tabular}

* $\mathrm{PET}_{\mathrm{R}}$ : bottle-grade poly(ethylene terephthalate), KL: kraft lignin, and ML: chemically modified lignin. 
sample (injected material) was heated in the alumina crucible $\left(25^{\circ} \mathrm{C}\right.$ to $\left.400{ }^{\circ} \mathrm{C}\right)$ at a heating rate of $10{ }^{\circ} \mathrm{C} \mathrm{min}^{-1}$ under a

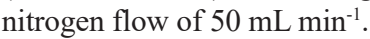

\subsection{Tensile measurements}

The tensile tests were performed according to the ISO 527-1:2012 (type 5A specimen) standard. The tests were conducted at the facilities of the Federal University of Espírito Santo (UFES)/LABPETRO using a Lloyd Instruments LR5K Plus universal testing machine. The measurement conditions were a load cell of $5 \mathrm{kN}$, a $50 \mathrm{~mm}$ strain gauge with a measurable deformation of $25 \mathrm{~mm}$, and a crosshead speed of $1 \mathrm{~mm} \mathrm{~min}^{-1}$.

\section{Results and Discussion}

\subsection{ATR-FTIR}

Figure S1a (see Supplementary Material) shows the ATR-FTIR spectra of the KL and ML samples, and the main bands and respective assignments are listed in Table 2 and Table 3. Figure S1a shows significant differences between the ATR-FTIR spectra of ML and KL samples - one of them is the absence of the band at $1710 \mathrm{~cm}^{-1}$ in the ML spectrum, exhibited by unmodified lignin (KL), which is attributed to the vibration of the carbonyl group conjugated to the aromatic ring. Instead, ML has two high-intensity bands, at 1598 and $1416 \mathrm{~cm}^{-1}$, assigned to the carboxylate anion. The appearance of these intense bands demonstrates the efficiency of the carboxylation process in the modification reaction. The KL and ML samples both exhibited bands related to the stretching and in-plane bending of the $\mathrm{CH}_{2}$ group, at 2938 and $1453 \mathrm{~cm}^{-1}$, respectively, (Tabs. 2 and 3), indicating that these groups did not participate in the chemical reaction. The main bands of the $\mathrm{PET}_{\mathrm{R}}$ polymer matrix as well as its $\mathrm{PET}_{\mathrm{R}} / \mathrm{KL}$ and $\mathrm{PET}_{\mathrm{R}} / \mathrm{ML}$ lignin blends are assigned in Table $\mathrm{S} 1$.

\subsection{TGA}

Figure 1a depicts the TGA curves of KL and ML. Mass losses of approximately $6 \mathrm{wt} . \%$ for KL and $22 \mathrm{wt} . \%$ for ML were observed at around $100{ }^{\circ} \mathrm{C}$. This weight drop can be attributed to moisture loss. The chemical decomposition of $\mathrm{KL}$ and ML occurs over a wide temperature range, with the most intense mass loss being observed between $200^{\circ} \mathrm{C}$ and
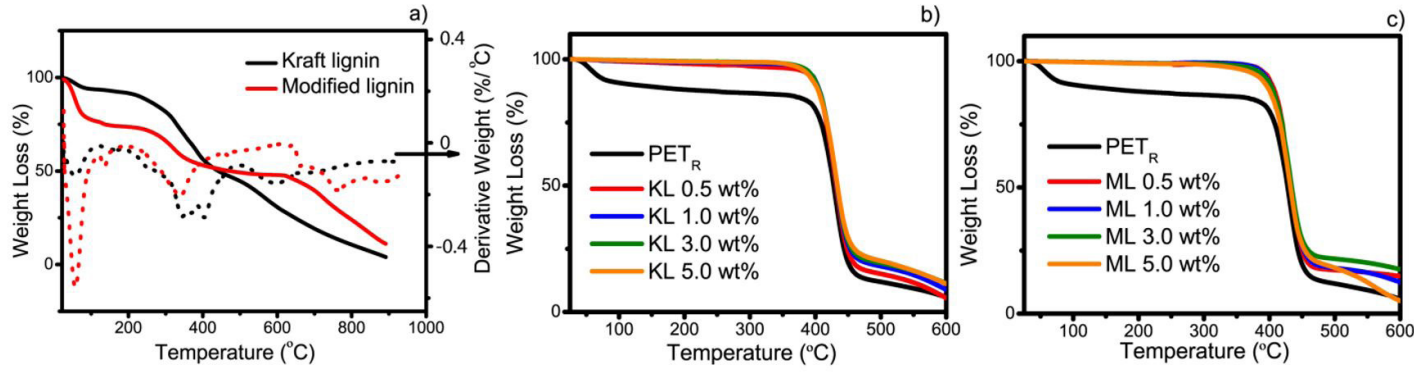

Figure 1. (a) TGA curves of the unmodified lignin (KL), modified lignin (ML), and $\mathrm{PET}_{\mathrm{R}}$ and their own blends of (b) $\mathrm{PET}_{\mathrm{R}} / \mathrm{KL}$ and (c) $\mathrm{PET} \mathrm{R}_{\mathrm{R}} / \mathrm{ML}$.

Table 2. Assignments of the vibrational bands of the lignin $(\mathrm{KF})^{[23-25]}$.

\begin{tabular}{cc}
\hline Wavenumber $\left(\mathbf{c m}^{-1}\right)$ & Assignment \\
\hline 3413 & OH group (hydroxyl) \\
2934 & aliphatic $\mathrm{C}-\mathrm{H}$ asymmetric stretching \\
1710 & $\mathrm{C}=\mathrm{O}$ stretch of carboxylic acids, ketones, and aldehydes \\
1603 & $\mathrm{C}=\mathrm{C}$ aromatic stretching \\
1505 & $\mathrm{C}=\mathrm{C}$ aromatic stretching \\
1454 & $\mathrm{CH}_{2} \mathrm{CH}_{3}$ bending \\
1110 & $\mathrm{C}-\mathrm{O}$ phenolic stretching \\
1019 & C-O stretching of the aliphatic secondary alcohol chain \\
\hline
\end{tabular}

Table 3. Assignments of the vibrational bands of the modified lignin (ML) ${ }^{[23-25]}$

\begin{tabular}{cc}
\hline Wavenumber $\left(\mathbf{c m}^{-1}\right)$ & Assignment \\
\hline 3254 & OH group (hydroxyl) \\
2938 & aliphatic C-H asymmetric stretching \\
1598 & asymmetric carboxylate stretching \\
1416 & symmetrical carboxylate stretch \\
1453 & $\mathrm{C}=\mathrm{C}$ aromatic stretches \\
1249 & $\mathrm{CH}_{2} \mathrm{CH}_{3}$ bending \\
1123 & $\mathrm{C}-\mathrm{O}$ phenolic stretching \\
1031 & C-O stretching of the aliphatic secondary alcohol chain \\
\hline
\end{tabular}


$700{ }^{\circ} \mathrm{C}$. In this temperature range, $\mathrm{KL}$ loses approximately 72 wt. $\%$, while ML loses about 34 wt. $\%{ }^{[23,26,27]}$. The wide range of thermal degradation of lignin can be explained by the different oxygenated functional groups in their structure, which provides different thermal stabilities ${ }^{[28]}$. The thermal degradation of lignin generally occurs in three main steps: 0 to $120{ }^{\circ} \mathrm{C}$, related to the evaporation of absorbed water, 180 to $350{ }^{\circ} \mathrm{C}$, associated with the degradation of carbohydrates, which are converted into volatile gases such as $\mathrm{CO}, \mathrm{CO}_{2}$ and $\mathrm{CH}_{4}$, and above $350^{\circ} \mathrm{C}$, related to the degradation of lignin-derived products together with the removal of produced gases ${ }^{[28]}$.

Due to the complexity of lignin's structure, the chemical decomposition of this material involves several competing reactions. Lignin contains several chemical subunits within its macromolecule. During the thermal degradation process, chemical bonds of different bond energies are broken ${ }^{[23,26,27]}$.

The dehydration of lignin prevails in its thermal degradation pathways. Dehydration of the lignin structure results in pyrolysis products with unsaturated side chains ${ }^{[28]}$. Carbon monoxide, carbon dioxide, and methane are also formed during these processes ${ }^{[29,30]}$. The decomposition of aromatic rings occurs above $400{ }^{\circ} \mathrm{C}^{[31]}$. Prolonged heating above $400{ }^{\circ} \mathrm{C}$ leads to saturation of aromatic rings, the disruption of $\mathrm{C}-\mathrm{C}$ bonds, and the release of smaller molecules, such as water, $\mathrm{CO}_{2}$, and $\mathrm{CO}$, accompanied by the rearrangement and condensation of the aromatic rings within the lignin structural units ${ }^{[29]}$.

Figure 1a shows 1 a plot of the first derivative of the mass loss versus temperature for the KL and ML samples. One can conclude that the KL sample is thermally more stable than the ML sample due to the highest temperature of maximum weight loss related to the lignin carbohydrate degradation appeared at $320{ }^{\circ} \mathrm{C}$ for the ML sample but appeared in the interval between $320^{\circ} \mathrm{C}$ to $380{ }^{\circ} \mathrm{C}$ for the KL sample.

According to Kindsigo and Kallas ${ }^{[32]}$, at ambient temperature in the presence of oxygen and water, it is possible to observe the degradation of lignin via wet oxidation, which is increased with elevated temperatures. In the analyzed temperature range of $110-190{ }^{\circ} \mathrm{C}$, the lignin degradation was $20 \%$ at $110^{\circ} \mathrm{C}$ and $53 \%$ at $190{ }^{\circ} \mathrm{C}$; thus, it is expected that at higher temperatures the degradation rate would continue to increase. In this way, the chemical modification of lignin through carboxylate anion incorporation favors the incorporation of water molecules into its structure due to the higher hydrophilicity of the carboxylated lignin sample (ML sample), making it more unstable and resulting in faster degradation. The total mass losses of the KL and ML samples when heated to $900{ }^{\circ} \mathrm{C}$ were $96 \mathrm{wt} . \%$ and $88 \mathrm{wt} . \%$, respectively. One can also see from Figure $2 \mathrm{a}$ that the lignin continued to decompose at temperatures higher than $900{ }^{\circ} \mathrm{C}$.

Figures $1 \mathrm{~b}$ and $1 \mathrm{c}$ compare the TGA curve of $\mathrm{PET}_{\mathrm{R}}$ with those of the $\mathrm{PET}_{\mathrm{R}} / \mathrm{KL}$ (Figure 1b) and $\mathrm{PET}_{\mathrm{R}} / \mathrm{ML}$ (Figure 1c) blends. The results of the TGA measurements demonstrate that the admixing of KL and ML into the $\mathrm{PET}_{\mathrm{R}}$ to form a blend caused a shift in the onset temperature of thermal degradation $\left(450^{\circ} \mathrm{C}\right)$, whereas the $\mathrm{PET}_{\mathrm{R}}$ sample exhibited two mass loss events: the first one in the temperature range of $50{ }^{\circ} \mathrm{C}$ to $100{ }^{\circ} \mathrm{C}$ (mass loss of $12.5 \mathrm{wt} . \%$ ) and the second one in the temperature range of $400{ }^{\circ} \mathrm{C}$ to $450{ }^{\circ} \mathrm{C}$ (mass loss of $75 \mathrm{wt} . \%$ ). As a consequence, these blends presented a higher residual mass than $\mathrm{PET}_{\mathrm{R}}$ (20-25 wt.\% versus $12.5 \mathrm{wt} . \%$ ) at $450{ }^{\circ} \mathrm{C}$.

The increase in the onset temperature of thermal degradation of the $\mathrm{PET}_{\mathrm{R}}$ /lignin blends in relation to neat $\mathrm{PET}_{\mathrm{R}}$ may be attributed to the chemical compatibility between the $\mathrm{PET}_{\mathrm{R}}$ and $\mathrm{KL}$ and ML fillers due to the aromatic structure present in both sample types. However, the moisture present in the lignin blends increases the mass loss content in this temperature range, as our results show (see Figure 1a) with degradation temperatures above $450{ }^{\circ} \mathrm{C}$.

\subsection{Differential Scanning Calorimetry (DSC)}

Figure 2a shows the DSC curves of KL and ML. Typically, the $T_{g}$ values of unmodified lignins vary from 90 to $180^{\circ} \mathrm{C}^{[33,34]}$. The significant enthalpy relaxation process that usually occurs in polymers during DSC scanning makes it challenging to determine the $T_{g}$ value of lignin from the DSC measurements. Complex hydrogen bonding interactions and the highly amorphous structure of kraft lignin favor enthalpy relaxation. This is detected in the interval where a slope change occurs in the heating curve ${ }^{[35-37]}$. The $\mathrm{T}_{\mathrm{g}}$ values of $\mathrm{KL}$ and $\mathrm{ML}$ are $100{ }^{\circ} \mathrm{C}$ and $127{ }^{\circ} \mathrm{C}$, respectively (Figure $2 \mathrm{a}$ ). Table 4 summarizes the thermal properties of the studied samples obtained from the DSC measurements, such as the glass transition temperature $\left(\mathrm{T}_{\mathrm{g}}\right)$, crystallization temperature $\left(\mathrm{T}_{\mathrm{c}}\right)$, melting

Table 4. DSC results for $\mathrm{PET}_{\mathrm{R}}$ and $\mathrm{PET} / \mathrm{KL}$ and PET/ML blends.

\begin{tabular}{lccccc}
\hline \multicolumn{1}{c}{ Sample } & $\mathbf{T}_{\mathbf{g}}\left({ }^{\circ} \mathbf{C}\right)^{*}$ & $\mathbf{T}_{\mathbf{c}}\left({ }^{\circ} \mathbf{C}\right)^{*}$ & $\mathbf{T}_{\mathbf{m}}\left({ }^{\circ} \mathbf{C}\right)^{*}$ & $\Delta \mathbf{H}_{\mathbf{m}}(\mathbf{J} / \mathbf{g})^{*}$ & $\mathbf{X}_{\mathbf{c}}(\mathbf{\%})^{*}$ \\
\hline PET $_{\mathrm{R}}$ & 63.30 & 119.50 & 253.79 & -4.45 & $3.18 \%$ \\
PET/KF 0.5wt.\% & 70.29 & 117.37 & 257.18 & -4.90 & $3.52 \%$ \\
PET/KF 1.0wt.\% & 69.70 & 116.42 & 256.59 & -5.49 & $3.96 \%$ \\
PET/KF 3.0wt.\% & 68.34 & 116.89 & 256.49 & -5.89 & $4.34 \%$ \\
PET/KF 5.0wt.\% & 68.80 & 117.99 & 253.09 & -5.94 & $4.46 \%$ \\
PET/ML 0.5wt.\% & 74.96 & 113.61 & 255.02 & -5.71 & $4.10 \%$ \\
PET/ML 1.0wt.\% & 74.76 & 113.05 & 258.26 & -5.26 & $3.80 \%$ \\
PET/ML 3.0wt.\% & 74.77 & 110.46 & 258.15 & -5.66 & $4.17 \%$ \\
PET/ML 5.0wt.\% & 74.98 & 109.45 & 256.34 & -5.70 & $4.29 \%$ \\
\hline
\end{tabular}

${ }^{*} \mathrm{~T}_{\mathrm{g}}, \mathrm{T}_{\mathrm{c}}, \mathrm{T}_{\mathrm{m}}, \Delta \mathrm{H}_{\mathrm{m}}$ and $\mathrm{X}_{\mathrm{c}}$ correspond to glass transition temperature, crystallization temperature, melting temperature, melting enthalpy, and degree of crystallinity, respectively. 
temperature $\left(\mathrm{T}_{\mathrm{m}}\right)$, melting enthalpy $\left(\Delta \mathrm{H}_{\mathrm{m}}\right)$, and degree of crystallinity $\left(\mathrm{X}_{\mathrm{c}}\right)$.

The variation in the values of $\mathrm{T}_{\mathrm{g}}, \mathrm{T}_{\mathrm{c}}$, and $\mathrm{T}_{\mathrm{m}}$ of the blends in relation to those of $\mathrm{PET}_{\mathrm{R}}$ show a clear dependence on both the type and the amount of lignin added. The $\mathrm{PET}_{\mathrm{R}}$ sample exhibited $\mathrm{T}_{\mathrm{g}}, \mathrm{T}_{\mathrm{c}}$, and $\mathrm{T}_{\mathrm{m}}$ values of $63.3,119.5$, and $253.8^{\circ} \mathrm{C}$, respectively, which are typical for this polymer. The DSC curves (Figure 2b, c) for the blends also showed well-defined endothermic peaks of glass transition, exothermic cold crystallization, and endothermic melting peaks, which is characteristic of PET.

In general, $\mathrm{PET}_{\mathrm{R}} / \mathrm{KL}$ blends exhibited higher $\mathrm{T}_{\mathrm{g}}$ and $\mathrm{T}_{\mathrm{m}}$ values (approximately $70{ }^{\circ} \mathrm{C}$ and $257^{\circ} \mathrm{C}$, respectively) compared with those of $\mathrm{PET}_{\mathrm{R}}$. This shift of the glass and melting transitions to higher temperatures was somewhat larger in the case of $\mathrm{PET}_{\mathrm{R}} / \mathrm{ML}$ for $\mathrm{T}_{\mathrm{m}}$ (approximately $258^{\circ} \mathrm{C}$ ) and was notably larger for $\mathrm{T}_{\mathrm{g}}$ (about $75^{\circ} \mathrm{C}$ ), except for the $\mathrm{PET}_{\mathrm{R}} / \mathrm{ML} 5.0$ wt.\% sample. On the whole, the $\mathrm{PET}_{\mathrm{R}} / \mathrm{ML}$ blends showed more stable melt characteristics (melting temperatures and melting enthalpies) compared to those of the $\mathrm{PET}_{\mathrm{R}} / \mathrm{KL}$ blends.

The value of $\mathrm{T}_{c}$ presented a maximum decrease in three units $\left(119.5 \rightarrow 116.4{ }^{\circ} \mathrm{C}\right)$ of temperature for the $\mathrm{PET}_{\mathrm{R}} / \mathrm{KL} 1.0 \mathrm{wt} . \%$ blend, while in the $\mathrm{PET}_{\mathrm{R}} / \mathrm{ML}$ blends, the most significant variation was $\mathrm{T}_{\mathrm{c}}=114 \rightarrow 110^{\circ} \mathrm{C}$ (Table 5). The cold crystallization temperatures of the blends showed an opposite trend from the melting temperatures, where the cold crystallization temperatures of the $\mathrm{PET}_{\mathrm{R}} / \mathrm{KL}$ and $\mathrm{PET}_{\mathrm{R}} / \mathrm{ML}$ samples were decreased in comparison to that of $\mathrm{PET}_{\mathrm{R}}$. This temperature reduction was notably larger in the $\mathrm{PET}_{\mathrm{R}} / \mathrm{ML}$ blends.
The lignin macromolecule contains polar groups capable of producing chemical interactions to become closer to the $\mathrm{PET}_{\mathrm{R}}$ chains. These secondary forces may have contributed to the increase of $\mathrm{T}_{\mathrm{g}}$ and $\mathrm{T}_{\mathrm{m}}$ for the studied blends. The $\mathrm{PET}_{\mathrm{R}} / \mathrm{ML}$ blends presented higher increases in these two parameters in relation to the $\mathrm{PET}_{\mathrm{R}} / \mathrm{KL}$ blends, probably due to the incorporation of carboxylate groups in the lignin, favoring its chemical interaction with the PET matrix, and consequently, increasing the $\mathrm{T}_{\mathrm{g}}$ and $\mathrm{T}_{\mathrm{m}}$ values ${ }^{[38,39]}$.

Miscibility is a crucial parameter to be achieved in polymer blends to improve the properties of homopolymers. In our study, a single $\mathrm{T}_{\mathrm{g}}$ was observed in the DSC curves of the blends, which is indicative of miscibility. The polarity of the lignin molecules results in strong interactions between them that hinder their miscibility with other polymers. To maintain miscibility, interaction forces between the polymer matrix (PET in our case) and lignin are required. Generally, PET has the ability to interact with lignin through $\pi$ electronic interactions favoring the miscibility between them. Hydrogen bonds that eventually form between PET and lignin polar groups also facilitate miscibility. For this reason, lignin surface chemical modification is typically performed to reduce the interaction forces between the lignin molecules, attaching them to hydrophilic polymer matrices, such as $\mathrm{PET}_{\mathrm{R}}$.

The degree of crystallinity is another important property of semi-crystalline thermoplastics that is directly related, among others, to the mechanical properties of plastics. The degree of crystallinity by DSC of the studied blends was assessed using the following Equation 1:

$$
\boldsymbol{X}_{c}=\frac{\Delta \boldsymbol{H}_{\boldsymbol{m}}-\Delta \boldsymbol{H}_{\boldsymbol{c}}}{\Delta \boldsymbol{H}_{\boldsymbol{m}}^{0}} * 100 \%
$$

Table 5. Tensile test results for $\mathrm{PET}_{\mathrm{R}}$ and $\mathrm{PET}_{\mathrm{R}} / \mathrm{KL}$ and $\mathrm{PET}_{\mathrm{R}} / \mathrm{ML}$ blends.

\begin{tabular}{|c|c|c|c|c|c|c|}
\hline Sample & $\mathbf{E}(\mathbf{G P a}) *$ & $\Delta \mathbf{E}(\mathbf{G P a})^{* *}$ & $\sigma(\text { Мра })^{* *}$ & $\Delta \sigma(\text { Мрa })^{* *}$ & $\varepsilon_{\text {rup }} \% * *$ & $\Delta \varepsilon_{\text {rup }} \% * *$ \\
\hline $\mathrm{PET}_{\mathrm{R}}$ & 1.33 & \pm 0.04 & 57.31 & \pm 0.60 & $\mathrm{NB}^{*}$ & $\mathrm{NB}^{*}$ \\
\hline PET/KF 0.5 wt.\% & 1.47 & \pm 0.06 & 60.20 & \pm 0.85 & $\mathrm{NB}^{*}$ & $\mathrm{NB}^{*}$ \\
\hline PET/KF 1.0 wt. $\%$ & 1.55 & \pm 0.05 & 61.62 & \pm 0.67 & $\mathrm{NB}^{*}$ & $\mathrm{NB}^{*}$ \\
\hline PET/KF 3.0 wt. $\%$ & 1.71 & \pm 0.05 & 39.56 & \pm 1.28 & 2.0 & \pm 0.54 \\
\hline PET/KF 5.0 wt. $\%$ & 1.76 & \pm 0.12 & 37.77 & \pm 2.80 & 2.1 & \pm 0.29 \\
\hline PET/ML 0.5 wt. $\%$ & 1.66 & \pm 0.29 & 20.59 & \pm 3.60 & 0.9 & \pm 0.16 \\
\hline PET/ML 1.0 wt. $\%$ & 1.43 & \pm 0.22 & 20.41 & \pm 1.78 & 1.1 & \pm 0.40 \\
\hline
\end{tabular}

*did not break; **E: modulus of elasticity; $\Delta \mathrm{E}$ : standard deviation of modulus of elasticity; $\sigma$ : maximum tensile strength; $\Delta \sigma$ : standard deviation of maximum tensile strength; हrup: strain at break; $\Delta$ srup: standard deviation of strain at break.

a)

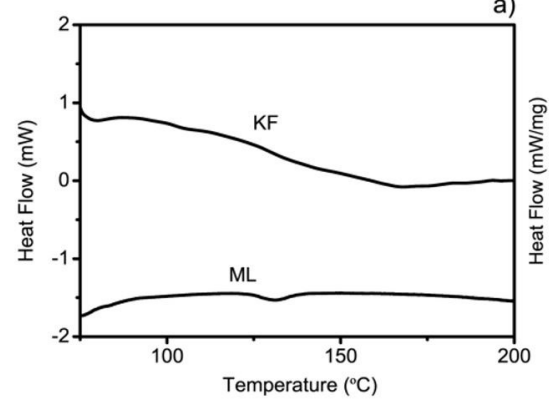

b)

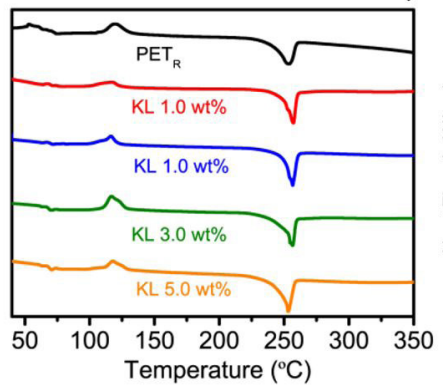

c)

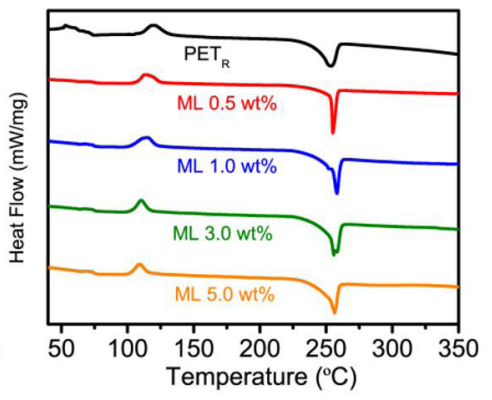

Figure 2. DSC plots for KL and ML (a) lignin; (b-c) $P T_{R}$ and their respective blends of (b) $P E T_{R} / K L$ and (c) $P E T_{R} / M L$. 
In this equation, the difference between the measured heats of melting, $\Delta \mathrm{H}_{\mathrm{m}}$, and the cold crystallization, $\Delta \mathrm{H}_{\mathrm{c}}$, define the fusion enthalpy of a sample. The term $\Delta \mathrm{H}_{\mathrm{m}}{ }^{0}$ is a reference value and represents the heat of melting if the polymer were $100 \%$ crystalline. The value $\Delta \mathrm{H}_{\mathrm{m}}{ }^{0}=140 \mathrm{~J} \mathrm{~g}^{-1}$ was used ${ }^{[38]}$.

All samples exhibited low values of $\mathrm{X}_{\mathrm{c}}$ (see Table 4). Two different factors could have affected the overall crystallinity of the samples. The first one is related to the production process of the specimens, which was by injection molding. Significant differences between the injection and molding temperatures resulted in a predominantly amorphous sample structure because the polymer chains did not have enough time for periodic ordering. On the other hand, the presence of KL and ML lignin favored the crystallization of $\mathrm{PET}_{\mathrm{R}}$, indicating that lignin acted as a nucleating agent to the PET domains ${ }^{[39]}$.

\subsection{Tensile tests}

The results of the mechanical tensile tests, including the modulus of elasticity $(E)$, maximum tensile strength $(\sigma)$, and strain at break (erup), are shown in Table 5.

The $\sigma$ parameter (maximum tensile strength) of a polymer blend indicates the tension transfer capacity from the matrix to the filler, where the higher the interaction between phases, the higher the maximum tensile strength. The chemical modification of lignin did not produce efficient interfacial molecular interactions between the PET and ML components or, consequently, an enhancement in the mechanical properties of the $\mathrm{PET}_{\mathrm{R}} / \mathrm{ML}$ blends, as is seen from the experimental data (Table 5). Moreover, higher contents of $\mathrm{KL}$ in polymer blends $(<3.0 \mathrm{wt} \%)$ also seemed to be unfavorable for the strength and deformability of the $\mathrm{PET}_{\mathrm{R}} / \mathrm{KL}$ blends. Formulations containing $3 \mathrm{wt} . \%$ and 5 wt. $\%$ of ML could not be tested at all, as the mixture of ML with $\mathrm{PET}_{\mathrm{R}}$ in these proportions resulted in specimens forming cracks even before the mold was withdrawn.

In contrast, Young's modulus of all $\mathrm{PET}_{\mathrm{R}} / \mathrm{KL}$ blends followed the fundamental law of mixtures and was nearly the additive function of the composition. On the other hand, lignin, which is more rigid than $\mathrm{PET}_{\mathrm{R}}$, has the capacity to support the applied tension transferred from the polymeric matrix to itself, resulting in a higher Young's module of the respective blends in comparison with $\mathrm{PET}_{\mathrm{R}}{ }^{[40]}$.

Distinct from Young's modulus, the strength, and deformability of blends show more complex behavior. It is generally thought that these characteristics primarily depend on the strength of interfacial adhesion of the components, which is determined, in turn, by the mutual contact surface and the respective strength of interaction ${ }^{[41]}$. Water molecules can act as plasticizers to increase the mobility of lignin's polymer chains during its dispersion in the $\mathrm{PET}_{\mathrm{R}}$ matrix. There was a much finer dispersion of the KL phase than the ML phase in the respective blends, resulting in a higher contact surface between the KL and $\mathrm{PET}_{\mathrm{R}}$ molecules. However, the positive effects of $\mathrm{KL}$ on the tensile properties of the $\mathrm{PET}_{\mathrm{R}} / \mathrm{KL}$ blends seemed to diminish after the content of stiff KL chains exceeded a critical limit. We believe that the analogous critical limit was already attained for the lowest content of ML in the $\mathrm{PET}_{\mathrm{R}} / \mathrm{ML}$ samples with respect to Young's modulus of the material. As a result, a decreasing trend in the stiffness of $\mathrm{PET}_{\mathrm{R}} / \mathrm{ML}$ with the content of ML was observed.

\section{Conclusions}

In this study, kraft lignin (KL) and chemically modified kraft lignin (ML) were used to produce $\mathrm{PET}_{\mathrm{R}} /$ lignin blends. The results of ATR-FTIR, TGA, and DSC analyses verified the presence of chemical modifications in the ML samples. The TGA measurements indicated that KL was thermally more stable than ML, which is intrinsically linked to the ability of ML to absorb water, thus, increasing this material's susceptibility to degradation. Additionally, the water molecule absorption impacts the mechanical properties of the $\mathrm{PET}_{\mathrm{R}}$ /lignin blends, making the $\mathrm{PET}_{\mathrm{R}} / \mathrm{ML}$ blends more fragile than the $\mathrm{PET}_{\mathrm{R}} / \mathrm{KL}$ blends. The ATR-FTIR spectra of the blends showed no significant differences between them, while the DSC curves exhibited higher glass transition temperatures for the $\mathrm{PET}_{\mathrm{R}}$ /lignin blends compared with the $\mathrm{PET}_{\mathrm{R}}$ material.

$\mathrm{PET}_{\mathrm{R}} / \mathrm{KL}$ blends with small amounts of KL (up to approximately $1 \%$ ) showed improved mechanical properties. Both the modulus of elasticity and the maximum tensile strength of $\mathrm{PET}_{\mathrm{R}}$ benefited from the addition of lignin in this situation; this is the expected behavior of compatible polymer blends.

\section{Acknowledgements}

The authors thank FAPES for a scholarship to Lívia Lazzari, Fibria Celulose for supplying the lignin samples, and UFES/LABPETRO for the provision of laboratories and equipment. Letícia Silva and Joyce Araujo thank FAPERJ (grants E-26/201.978/2017 and E-26/202.746/2018) and CNPq (grant 311900/2017-8) for the fellowships.

\section{References}

1. Shah, A. A., Hasan, F., Hameed, A., \& Ahmed, S. (2008). Biological degradation of plastics: a comprehensive review. Biotechnology Advances, 26(3), 246-265. http://dx.doi. org/10.1016/j.biotechadv.2007.12.005. PMid:18337047.

2. Vanini, G., Castro, E. V. R., Silva, E. A., Fo., \& Romão, W. (2013). Despolimerização química de PET grau garrafa pósconsumo na presença de um catalisador catiônico, o brometo de hexadeciltrimetrilamônio (CTAB). Polímeros: Ciência e Tecnologia, 23(3), 425-431. http://dx.doi.org/10.4322/ polimeros.2013.084.

3. Abdul Aziz, F. M., Surip, S. N., Bonnia, N. N., \& Sekak, K. A. (2018). The effect of pineapple leaf fiber (PALF) incorporation into polyethylene terephthalate (PET) on FTIR, morphology and wetting properties. IOP Conference Series: Earth and Environmental Science, 105(1), 012082. http:// dx.doi.org/10.1088/1755-1315/105/1/012082.

4. Gadioli, R., Morais, J. A., Waldman, W. R., \& De Paoli, M.-A. (2014). The role of lignin in polypropylene composites with semi-bleached cellulose fibers: mechanical properties and its activity as antioxidant. Polymer Degradation \& Stability, 108 , 23-34. http://dx.doi.org/10.1016/j.polymdegradstab.2014.06.005.

5. Karmakar, S., De, S. K., \& Goswami, A. (2018). A pollution sensitive remanufacturing model with waste items: triangular dense fuzzy lock set approach. Journal of Cleaner Production, 187, 789-803. http://dx.doi.org/10.1016/j.jclepro.2018.03.161. 
6. Karagiannidis, P. G., Stergiou, A. C., \& Karayannidis, G. P. (2008). Study of crystallinity and thermomechanical analysis of annealed poly(ethylene terephthalate) films. European Polymer Journal, 44(5), 1475-1486. http://dx.doi.org/10.1016/j. eurpolymj.2008.02.024.

7. Romão, W., Franco, M. F., Bueno, M. I. M. S., \& De Paoli, M.-A. (2010). Distinguishing between virgin and postconsumption bottle-grade poly (ethylene terephthalate) using thermal properties. Polymer Testing, 29(7), 879-885. http:// dx.doi.org/10.1016/j.polymertesting.2010.05.009.

8. Romão, W., Franco, M. F., Bueno, M. I. M. S., Eberlin, M. N., \& De Paoli, M.-A. (2010). Analysing metals in bottlegrade poly(ethylene terephthalate) by X-ray fluorescence spectrometry. Journal of Applied Polymer Science, 117(5), 2993-3000. http://dx.doi.org/10.1002/app.32232.

9. Romão, W., Franco, M. F., Corilo, Y. E., Eberlin, M. N., Spinacé, M. A. S., \& De Paoli, M.-A. (2009). Poly (ethylene terephthalate) thermo-mechanical and thermo-oxidative degradation mechanisms. Polymer Degradation \& Stability, 94(10), 1849-1859. http:// dx.doi.org/10.1016/j.polymdegradstab.2009.05.017.

10. Romão, W., Franco, M. F., Iglesias, A. H., Sanvido, G. B., Maretto, D. A., Gozzo, F. C., Poppi, R. J., Eberlin, M. N., \& De Paoli, M.-A. (2010). Fingerprinting of bottle-grade poly(ethylene terephthalate) via matrix-assisted laser desorption/ionization mass spectrometry. Polymer Degradation \& Stability, 95(4), 666671. http://dx.doi.org/10.1016/j.polymdegradstab.2009.11.046.

11. Abdul Razak, N. C., Inuwa, I. M., Hassan, A., \& Samsudin, S. A. (2013). Effects of compatibilizers on mechanical properties of PET/PP blend. Composite Interfaces, 20(7), 507-515. http:// dx.doi.org/10.1080/15685543.2013.811176.

12. Kiziltas, A., Gardner, D. J., Han, Y., \& Yang, H.-S. (2011). Thermal properties of microcrystalline cellulose-filled PETPTT blend polymer composites. Journal of Thermal Analysis and Calorimetry, 103(1), 163-170. http://dx.doi.org/10.1007/ s10973-010-0894-6.

13. Torres-Huerta, A. M., Palma-Ramírez, D., Domínguez-Crespo, M. A., Del Angel-López, D., \& de la Fuente, D. (2014). Comparative assessment of miscibility and degradability on PET/PLA and PET/chitosan blends. European Polymer Journal, 61,285-299. http://dx.doi.org/10.1016/j.eurpolymj.2014.10.016.

14. Laurichesse, S., \& Avérous, L. (2014). Chemical modification of lignins: towards biobased polymers. Progress in Polymer Science, 39(7), 1266-1290. http://dx.doi.org/10.1016/j. progpolymsci.2013.11.004.

15. Chakar, F. S., \& Ragauskas, A. J. (2004). Review of current and future softwood kraft lignin process chemistry. Industrial Crops and Products, 20(2), 131-141. http://dx.doi.org/10.1016/j. indcrop.2004.04.016.

16. Haddad, M., Bazinet, L., Savadogo, O., \& Paris, J. (2017). A feasibility study of a novel electro-membrane based process to acidify Kraft black liquor and extract lignin. Process Safety and Environmental Protection, 106, 68-75. http://dx.doi. org/10.1016/j.psep.2016.10.003.

17. Luiz, F. S., Scremin, F. R., Werncke, E., Basso, R. L. O., Possan, E., \& Bittencourt, P. R. S. (2020). Thermal evaluation by DSC and tensile strength of extrudated blends from polyethylene terephthalate and kraft lignin. Waste and Biomass Valorization, 11(1), 367-373. http://dx.doi.org/10.1007/s12649-018-0367-x.

18. Glasser, W. G., Barnett, C. A., Muller, P. C., \& Sarkanen, K. V. (1983). The chemistry of several novel bioconversion lignins. Journal of Agricultural and Food Chemistry, 31(5), 921-930. http://dx.doi.org/10.1021/jf00119a001.

19. Sahoo, S., Misra, M., \& Mohanty, A. K. (2011). Enhanced properties of lignin-based biodegradable polymer composites using injection moulding process. Composites. Part A, Applied
Science and Manufacturing, 42(11), 1710-1718. http://dx.doi. org/10.1016/j.compositesa.2011.07.025.

20. Sameni, J., Krigstin, S., Jaffer, S. A., \& Sain, M. (2018). Preparation and characterization of biobased microspheres from lignin sources. Industrial Crops and Products, 117, 5865. http://dx.doi.org/10.1016/j.indcrop.2018.02.078.

21. Jeong, H., Park, J., Kim, S., Lee, J., \& Cho, J. W. (2012). Use of acetylated softwood kraft lignin as filler in synthetic polymers. Fibers and Polymers, 13(10), 1310-1318. http:// dx.doi.org/10.1007/s12221-012-1310-6.

22. Kadla, J. F., \& Kubo, S. (2004). Lignin-based polymer blends: analysis of intermolecular interactions in lignin-synthetic polymer blends. Composites. Part A, Applied Science and Manufacturing, 35(3), 395-400. http://dx.doi.org/10.1016/j. compositesa.2003.09.019.

23. Silva, L. G., Ruggiero, R., Gontijo, P. M., Pinto, R. B., Royer, B., Lima, E. C., Fernandes, T. H. M., \& Calvete, T. (2011). Adsorption of Brilliant Red 2BE dye from water solutions by a chemically modified sugarcane bagasse lignin. Chemical Engineering Journal, 168(2), 620-628. http://dx.doi.org/10.1016/j. cej.2011.01.040.

24. Edge, M., Wiles, R., Allen, N. S., McDonald, W. A., \& Mortlock, S. V. (1996). Characterisation of the species responsible for yellowing in melt degraded aromatic polyesters-I: yellowing of poly(ethylene terephthalate). Polymer Degradation \& Stability, 53(2), 141-151. http://dx.doi.org/10.1016/01413910(96)00081-X.

25. Silverstein, R. M., Webster, F. X., Kiemle, D. J., \& Bryce, D. L. (2014). Spectrometric identification of organic compounds. Hoboken: John Wiley \& Sons.

26. Grandmaison, J. L., Thibault, J., Kaliaguine, S., \& Chantal, P. D. (1987). Fourier-transform infrared spectrometry and thermogravimetry of partially converted lignocellulosic materials. Analytical Chemistry, 59(17), 2153-2157. http:// dx.doi.org/10.1021/ac00144a031.

27. Jakab, E., Faix, O., \& Till, F. (1997). Thermal decomposition of milled wood lignins studied by thermogravimetry/mass spectrometry. Journal of Analytical and Applied Pyrolysis, 40-41, 171-186. http://dx.doi.org/10.1016/S0165-2370(97)00046-6.

28. Brebu, M., \& Vasile, C. (2010). Thermal degradation of lignin: a review. Cellulose Chemistry and Technology, 44(9), 353-363.

29. Hoareau, W., Trindade, W. G., Siegmund, B., Castellan, A., $\&$ Frollini, E. (2004). Sugar cane bagasse and curaua lignins oxidized by chlorine dioxide and reacted with furfuryl alcohol: characterization and stability. Polymer Degradation \& Stability, 86(3), 567-576. http://dx.doi.org/10.1016/j. polymdegradstab.2004.07.005.

30. Meier, D., \& Faix, O. (1999). State of the art of applied fast pyrolysis of lignocellulosic materials: a review. Bioresource Technology, 68(1), 71-77. http://dx.doi.org/10.1016/S09608524(98)00086-8.

31. Rohella, R. S., Sahoo, N., Paul, S. C., Choudhury, S., \& Chakravortty, V. (1996). Thermal studies on isolated and purified lignin. Thermochimica Acta, 287(1), 131-138. http:// dx.doi.org/10.1016/0040-6031(96)02983-8.

32. Kindsigo, M., \& Kallas, J. (2006). Degradation of lignins by wet oxidation: model water solutions. Proceedings of the Estonian Academy of Sciences: Chemistry, 55(3), 132-144.

33. Irvine, G. M. (1985). The significance of the glass transition of lignin in thermomechanical pulping. Wood Science and Technology, 19(2), 139-149. http://dx.doi.org/10.1007/ BF00353074.

34. Lisperguer, J., Perez, P., \& Urizar, S. (2009). Structure and thermal properties of lignins: characterization by infrared spectroscopy and differential scanning calorimetry. Journal 
of the Chilean Chemical Society, 54(4), 460-463. http://dx.doi. org/10.4067/S0717-97072009000400030.

35. Awal, A., \& Sain, M. (2013). Characterization of soda hardwood lignin and the formation of lignin fibers by melt spinning. Journal of Applied Polymer Science, 129(5), 2765-2771. http:// dx.doi.org/10.1002/app.38911.

36. Cachet, N., Camy, S., Benjelloun-Mlayah, B., Condoret, J.S., \& Delmas, M. (2014). Esterification of organosolv lignin under supercritical conditions. Industrial Crops and Products, 58, 287-297. http://dx.doi.org/10.1016/j.indcrop.2014.03.039.

37. Gordobil, O., Delucis, R., Egüés, I., \& Labidi, J. (2015). Kraft lignin as filler in PLA to improve ductility and thermal properties. Industrial Crops and Products, 72, 46-53. http:// dx.doi.org/10.1016/j.indcrop.2015.01.055.

38. Canevarolo, S. V. (2010). Ciência dos polímeros: um texto básico para tecnólogos e engenheiros. São Paulo: Artliber

39. Wellen, R. M. R., Canedo, E. L., \& Rabello, M. S. (2012). Effect of styrene-co-acrylonitrile on cold crystallization and mechanical properties of poly(ethylene terephthalate). Journal of Applied Polymer Science, 125(4), 2701-2710. http://dx.doi. org/10.1002/app.36585.

40. Araujo, J. R., Mano, B., Teixeira, G. M., Spinacé, M. A. S., \& De Paoli, M.-A. (2010). Biomicrofibrilar composites of high density polyethylene reinforced with curauá fibers: Mechanical, interfacial and morphological properties. Composites Science and Technology, 70(11), 1637-1644. http://dx.doi.org/10.1016/j. compscitech.2010.06.006.

41. Makkam, S., \& Harnnarongchai, W. (2014). Rheological and mechanical properties of recycled PET modified by reactive extrusion. Energy Procedia, 56, 547-553. http://dx.doi. org/10.1016/j.egypro.2014.07.191.

Received: Dec. 04, 2018

Revised: Aug. 03, 2019

Accepted: Oct. 03, 2019 


\section{Supplementary Material}

Supplementary material accompanies this paper.

Figure S1. (a) ATR-FTIR spectra of lignin obtained by the kraft process (KL) and chemically modified lignin (ML); (b) PETR/kraft lignin (KL) blends; (c) PETR/modified lignin (ML) blends.

Table S1. Assignments of FTIR bands for PETR and their respective PETR/KL and PETR/ML blends $\left.{ }^{2-4}\right]$.

This material is available as part of the online article from http://www.scielo.br/po 